Article

\title{
Compound Droughts and Heat Waves in China
}

\author{
Lei Ye ${ }^{1}$, Ke Shi ${ }^{1}$, Zhuohang Xin ${ }^{1, *}$, Chao Wang ${ }^{2}$ and Chi Zhang ${ }^{1,3}$ \\ 1 School of Hydraulic Engineering, Dalian University of Technology, Dalian 116024, China; \\ yelei@dlut.edu.cn (L.Y.); shike@mail.dlut.edu.cn (K.S.); czhang@dlut.edu.cn (C.Z.) \\ 2 China Institute of Water Resources and Hydropower Research, Beijing 100038, China; wangchao@iwhr.com \\ 3 State Key Laboratory of Coastal and Offshore Engineering, Dalian University of Technology, \\ Dalian 116024, China \\ * Correspondence: xinzh@dlut.edu.cn; Tel.: +86-411-8470-7034
}

Received: 12 April 2019; Accepted: 10 June 2019; Published: 13 June 2019

check for updates

\begin{abstract}
Droughts and heat waves both are natural extreme climate events occurring in most parts of the world. To understand the spatio-temporal characteristics of droughts and heat waves in China, we examine changes in droughts, heat waves, and the compound of both during 1961-2017 based on high resolution gridded monthly sc_PDSI and daily temperature data. Results show that North China and Northwest China are the two regions that experience the most frequent droughts, while Central China is the least drought-affected region. Significant drought decreasing trends were mostly observed Qinghai, Xinjiang, and Tibet provinces, while the belt region between Yunnan and Heilongjiang provinces experienced significant drought increasing trends. Heat waves occur more frequently than droughts, and the increase of heat wave occurrence is also more obvious. The increasing of heat wave occurrence since the 2000s has been unprecedented. The compound droughts and heat waves were mild from the 1960s to 1980s, and began to increase in 1990s. Furthermore, the significant increasing trends of the percentage of compound droughts and heat waves to droughts are observed in entire China, and more than $90 \%$ drought occurrences are accompanied by one or more heat waves in the 2010s. The results highlight the increased percentage of compound droughts and heat waves and call for improved efforts on assessing the impact of compound extremes, especially in an era of changing climate.
\end{abstract}

Keywords: compound extremes; drought; heat wave; spatial distribution; temporal variation; trends

\section{Introduction}

Climate change is expected to cause the hydrologic cycle to speed up and intensify as warming global temperatures increase the rate of evaporation, in which many hydrological processes are deeply involved. Climate change may also alter the inherent characteristics of climate phenomena and increase the risk of climatic extremes [1]. The frequency and severity of climate extreme events have increased across many regions of the world in the past [2,3], and they are expected to further increase in the future based on various climate projections $[4,5]$.

Traditionally, estimations of the risks of climate extremes typically focus on an isolated process or variable, which is usually not capable to fully characterize the impact of extremes due to the fact that climatic variables are intrinsically interconnected. In addition, resilience, defined as the ability of a socio-environmental system to absorb disturbances, to withstand natural and anthropogenic hazards, and to reconfigure after a crucial disturbance [6], has achieved significant attention due to the fact that it allows multiple risks and their impacts on socio-environmental system and vulnerable people to be considered together in the context of development programming [7]. Recent studies have begun to explore trends and changes in compound extremes, such as droughts and heat waves [8-10], and these studies have recognized the necessity of jointly investigating climate events. Compound extremes, 
which are also referred to as simultaneous, concurrent, or coincident extremes, are commonly defined as the occurrence of multiple events that lead to extreme impacts [11-14].

Drought is a naturally recurring extreme climate event over land characterized by below-normal precipitation over a period of months to a few decades [15] and can have devastating impacts on regional water resources, agriculture, industry, and other social-ecological systems $[16,17]$. A heat wave is a period of abnormally high surface temperatures relative to those normally expected [18], spanning several days to several weeks, and can cause severe damage to society and the environment, with impacts on human health, air quality, energy demand, and agriculture $[19,20]$. Although droughts and heat waves span different time scales, their relationship is widely acknowledged [21], as they produce positive interaction and feedback together that intensify their effects [22,23]. Higher temperature accelerates potential evapotranspiration, resulting in more rapid moisture deficit and may increase drought severity by the increased vapor pressure deficit [23]. Concurrently, the moisture deficit reduces evaporative cooling leading to increased sensible heat flux and thus increases surface air temperature that may result in a heat wave or exaggerate its magnitude [24,25].

Due to the monsoon climate interacting with complex geographical conditions, China is frequently stricken by serious droughts and heat waves. Over the past few decades, droughts and heat waves have exerted profound economic and societal impacts in China. For instance, a severe drought over northern China in 1997 resulted in 226 days of zero flows in the Yellow River from Henan to Shandong provinces, and the total measured length without flow from the river mouth to upstream was about $687 \mathrm{~km}$ [26]. In the summer of 2011, severe droughts affected a combined 5.86 million hectares of crops, leaving a total of 9.17 million livestock and 12 million people short of drinking water [27]. Meanwhile, the frequency and intensity of hot extremes are increasing, with the five hottest summers in eastern China between 1950 and 2013 having all occurred after 2000 [28]. The record-breaking heat wave in 2013 in eastern China resulted in deaths among many cities and the estimated direct economic losses were about 59 billion RMB [29]. During the summer of 2013, more than 5000 heat wave-related illness cases were reported in China [30].

Although many previous studies have investigated the duration, tendency, and frequency of droughts and heat waves in national or regional scale in China, their work mostly focuses on either of them in isolation. However, studies suggest that the combined effect of compound extremes is stronger than individual extremes [31]. In addition, most of the work merely uses the data from ground-based meteorological stations, which are too sparse that huge uncertainties may arise due to interpolation. The characteristics of compound droughts and heat waves in China remains uncertain, which poses considerable challenges to water security and sustainable development, especially under changing climatic conditions. In this study, droughts are quantified using the self-calibrating Palmer Drought Severity Index (sc_PDSI), within the frame of one of the most widely used indices PDSI, which is considered to be more appropriate for global drought monitoring [32]. The sc_PDSI determines specific factors for each location separately, uniquely appropriate to that location, and produces fields of data that can be more validly inter-compared. Many studies have been conducted in China to evaluate and apply different drought indices, and the sc_PDSI is considered to be one of the best indices of drought $[33,34]$. Heat waves are defined as a period of time with daily maximum temperatures above a threshold, which is defined as a specific quantile in the temperature series rather than a fixed value for all the regions. The relative definition is more appropriate to characterize heat waves considering the significant differences of regional climatology over China. Our primary objective is to provide a comprehensive spatio-temporal analysis of compound droughts and heat waves in China using the most up-to-date high-resolution gridded data. The results of this paper will enhance our understanding of compound extremes and provide a reference for analyzing the mechanism of singleand multi-disaster, as well as assisting in strengthening the capacity to prevent and reduce the negative impacts of these meteorological disasters in China. 


\section{Material and Methodology}

\subsection{Study Area and Data Sources}

China is located in the southeastern Eurasian continent and belongs to the East Asian monsoon climate, covering approximately 9.6 million square kilometers and has the world's largest population. Due to complex natural and social conditions, China is divided into seven regions in Figure 1 according to natural and socioeconomic situations at the provincial scale like other studies [35]: Northeast China (NEC), North China (NC), Northwest China (NWC), Southwest China (SWC), Central China (CC), South China (SC), and East China (EC).

To analyze the most up-to-date drought and heat wave characteristics in China, the selected period ranges from 1961 to 2017, altogether 696 months. The sc_PDSI data are published by the Climatic Research Unit, University of East Anglia as the TS3.26 dataset (available at http://www.cru.uea.ac.uk/ data/) with a spatial resolution of $0.5^{\circ} \times 0.5^{\circ}$. The sc_PDSI in the TS3.26 dataset is calculated from time series of precipitation and temperature and fixed parameters related to the soil/surface characteristics at each location. Daily maximum temperature data at $0.5^{\circ} \times 0.5^{\circ}$ spatial resolution are obtained by the China Meteorological Administration (available at http://data.cma.cn/data/detail/dataCode/SURF_CLI_ CHN_TEM_DAY_GRID_0.5.html), which are interpolated using thin plate spline and 3D geospatial information from 2472 meteorological stations. The temperature dataset has been under rigorous quality control and no filtering or modification was made for this study. The temperature data is not available in Taiwan province and thus not discussed in this paper.

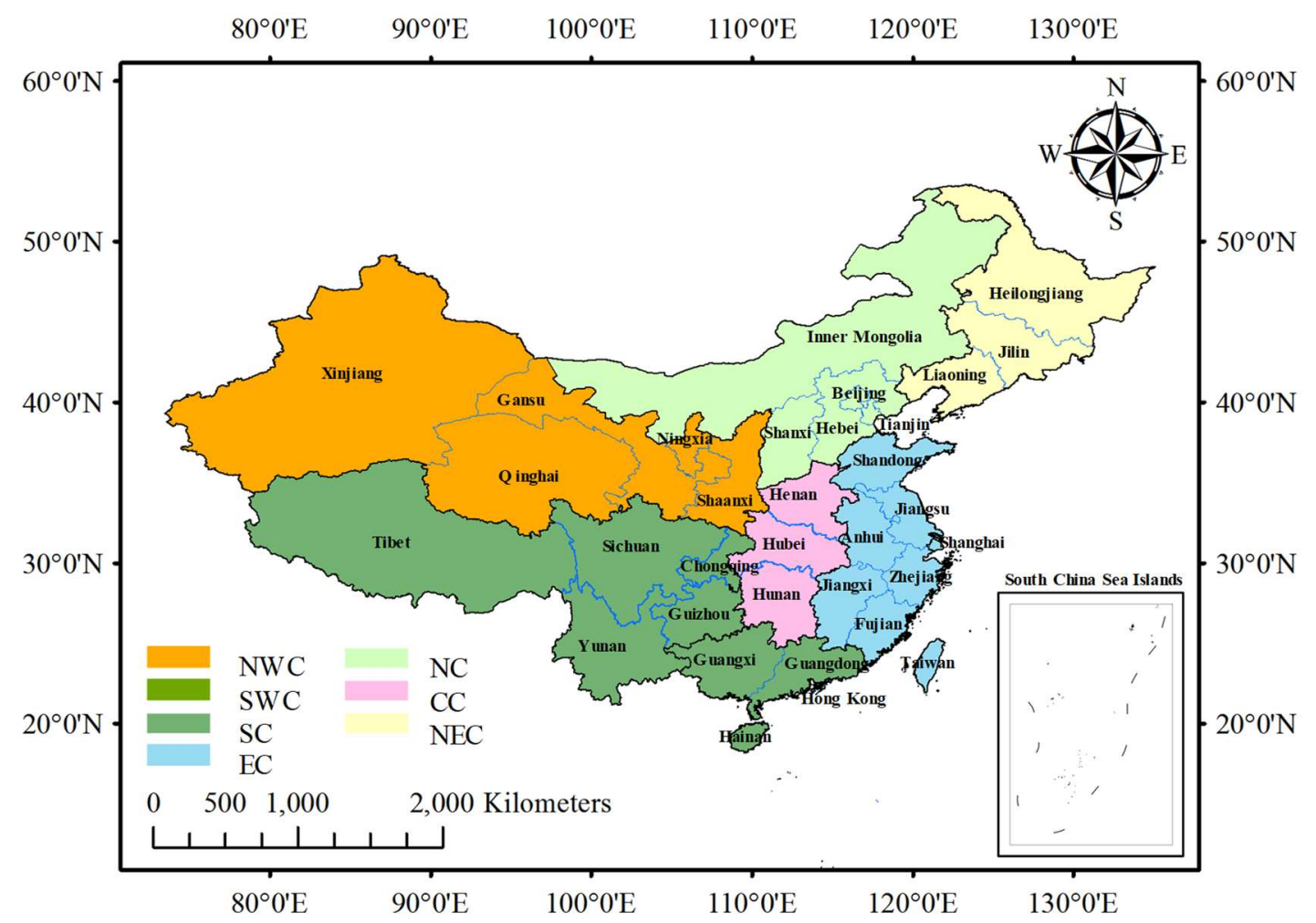

Figure 1. Seven regions of China.

\subsection{Evaluation of Heat Waves}

Generally, a period of several consecutive days with a maximum temperature above a threshold is regarded as a heat wave [10]. There is a consensus that 85 th or 90 th percentile for a given location can be used as a threshold for determining a heat wave [36-38]. In order to capture severer heat waves, the daily maximum temperature above the 90th percentile for at least six consecutive days is defined as a heat wave in this paper [39]. We only considered events that occurred during a five-month warm 
season (May-September) for heat waves, and the threshold values are statistically computed for each month and grid, respectively.

\subsection{Analysis of Compound Droughts and Heat Waves}

Drought is defined as sc_PDSI $\leq-1$; even when consecutive months have sc_PDSI $\leq-1$, it is only considered as a single drought event. Multi droughts can take place in one year as long as there is one month has sc_PDSI $>-1$ among the consecutive drought months. When there is one or more heat waves that happen during a drought period, we consider this a compound drought and heat wave, thus ensuring that the numbers of droughts and heat waves are always no fewer than the number of compound droughts and heat waves.

\subsection{Trend Free Prewhitening Mann-Kendall Nonparametric Test}

The Mann-Kendall (MK) nonparametric test, proposed by Mann [40] and then modified by Kendall [41], is based on the correlation between the ranks of a time series and their chronological order. The MK test has the advantage of being rarely disturbed by outliers, it is easy to calculate, and it does not assume any special form for the probability distribution function of the data [42].

However, some hydrological time series may usually have a serial correlation, which will increase the probability that the MK test detects a significant trend, leading to a disproportionate rejection of the null hypothesis of no trend, whereas the null hypothesis is actually true [43]. On this basis, Serinaldi et al. [44] compared the results of standard and improved versions of the MK test, and emphasized the effect of serial correlation on trend detection. Clarke [45] also pointed out the problem of circular reasoning in hydrological statistics and the failure to account for spatial correlations between variables. Poppick et al. [46] took the temperature trend as an example to compare parametric statistical methods and nonparametric methods. Therefore, Trend Free Prewhitening MK (TFPW-MK) [43], which detrends and pre-whitens the time series before the MK test, is adopted in this paper.

The time series shows an increasing trend when statistic $Z$ is greater than 0 , while the trend is decreasing when $Z$ is less than 0 . In the bilateral trend test, if $|Z| \geq Z_{1-\alpha / 2}$ at a given $\alpha$ confidence level, the original hypothesis of no trend is unacceptable. The $Z$ values of \pm 1.96 , and \pm 1.64 are equal to the confidence levels of 0.05 , and 0.1 , respectively. Based on these confidence levels, the detected trend could be classified into six zones according to $Z$ value [47]: (1) $Z<-1.96$, indicating significant decreasing trend; (2) $Z \in[-1.96$ to -1.64 ), indicating weak decreasing trend; (3) $Z \in[-1.654$ to 0 ), indicating no significant decreasing trend; (4) $Z \in(0$ to 1.64], indicating no significant increasing trend; (5) $Z \in$ (1.64 to 1.96], indicating weak increasing trend; (6) $Z>1.96$, indicating the significant increasing trend.

\section{Results}

\subsection{Droughts}

To better understand the drought patterns over China, the annual average number of drought occurrences at the decadal level for seven regions is presented in Figure 2 and Table 1. There were three areas in China that experienced frequent droughts in the 1960s, the first and severest was the west part of China mainly including Xinjiang, Qinghai, Tibet, and Sichuan provinces, the second was part of northeastern Inner Mongolia province, and the last was SC and the south half of EC. In the 1970s, NWC continued to be the severest drought-affected region with the annual average number of drought occurrences equal to 0.76 . Frequent droughts were still observed in the Tibet and Sichuan provinces in SWC. The drought frequency increased a lot in NEC and its adjacent area in northern NC, while drought frequency reduced more than $30 \%$ in SC and EC. NC became the most frequent drought-affected region in the 1980s throughout China as most of Inner Mongolia and Hebei provinces experienced very high drought frequency. In the 1990s, except that drought frequency increased in Ningxia, Shanxi, and Qinghai provinces in NWC, an obvious drought reduction was observed in 
almost entire China. Drought aggravated in NC and NEC in the 2000s, as most of the two regions suffered from high frequent droughts. In the 2010s, the drought alleviated significant over China, as SWC was the only region that presented drought increasing, drought reduced to various degrees in the rest of the six regions. For the entire study period, NC and NWC were the two regions that experienced the most frequent droughts, while the $\mathrm{CC}$ was the least drought-affected region.
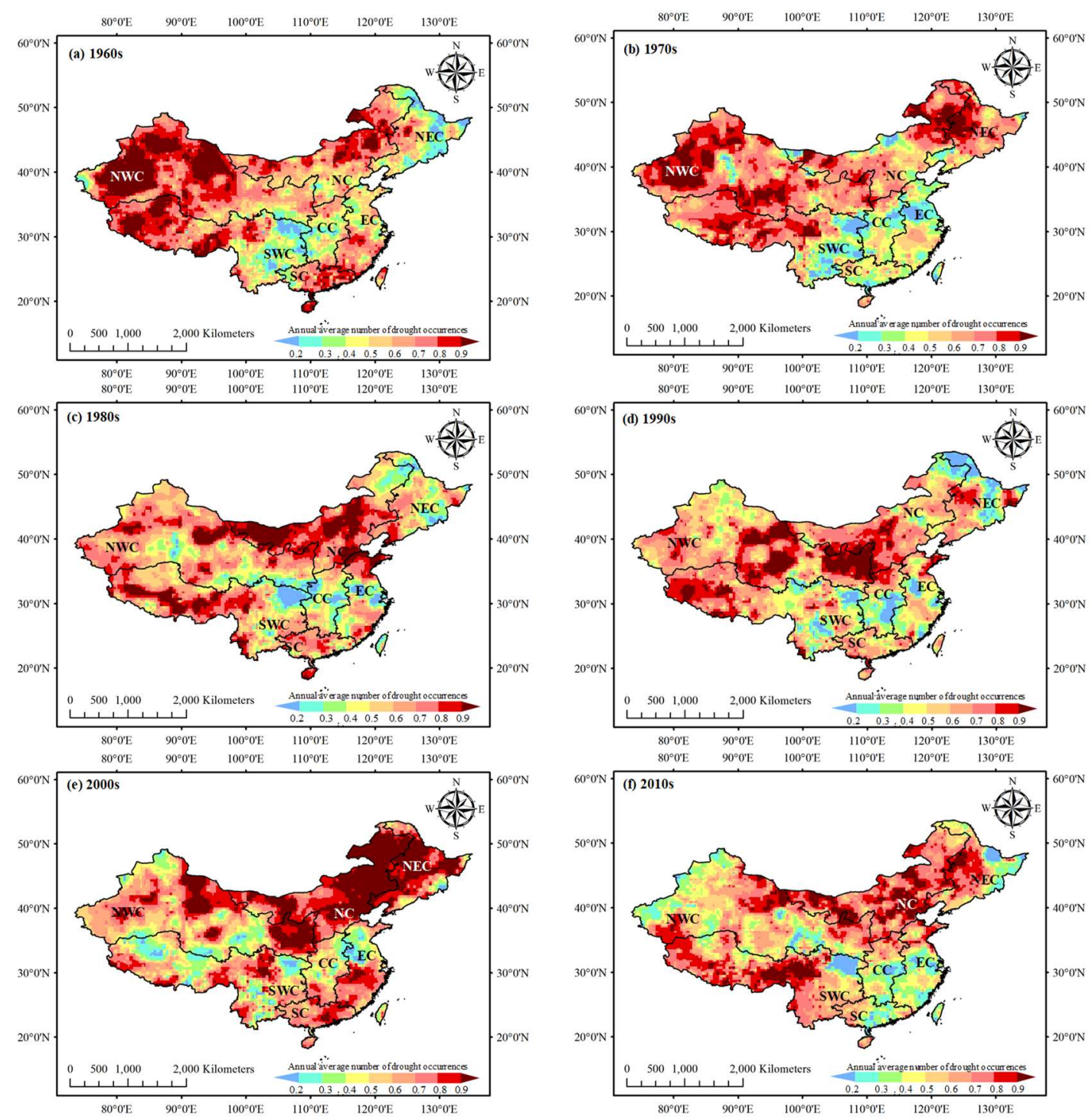

Figure 2. Spatial distribution of annual average number of drought occurrences at decadal level: (a) 1960s, (b) 1970s, (c) 1980s, (d) 1990s, (e) 2000s, and (f) 2010s.

Table 1. Annual average number of drought occurrences for the seven regions at the decadal level.

\begin{tabular}{cccccccc}
\hline Region & 1960s & 1970s & 1980s & 1990s & 2000s & 2010s & 1960s-2010s \\
\hline NEC & 0.45 & 0.70 & 0.54 & 0.50 & 0.84 & 0.61 & 0.61 \\
NC & 0.70 & 0.67 & 0.76 & 0.66 & 0.90 & 0.79 & 0.75 \\
NWC & 0.78 & 0.76 & 0.63 & 0.69 & 0.65 & 0.57 & 0.68 \\
SWC & 0.64 & 0.62 & 0.64 & 0.60 & 0.56 & 0.68 & 0.62 \\
CC & 0.48 & 0.42 & 0.44 & 0.45 & 0.54 & 0.48 & 0.47 \\
SC & 0.73 & 0.45 & 0.68 & 0.62 & 0.74 & 0.48 & 0.62 \\
EC & 0.60 & 0.42 & 0.57 & 0.50 & 0.62 & 0.48 & 0.53 \\
\hline
\end{tabular}


The above analyses focus on the frequency of drought occurrence in China, while drought occurs with spatio-temporal variation in frequency, severity, and duration. Therefore, Figure 3 depicts the spatial structure of sc_PDSI trends during 1960-2017, which can effectively consider all the features. TFPW-MK trend test was applied to the monthly sc_PDSI series at each grid over entire China, and then, the color of each grid was assigned according to the category of $Z$ value. The increasing and decreasing drought trends were almost impartial over entire China. Significant drought decreasing trends (i.e., increase of sc_PDSI) were mostly observed Qinghai, Xinjiang, and Tibet provinces, while the belt region between Yunnan and Heilongiiang provinces experienced significant drought increasing trends.

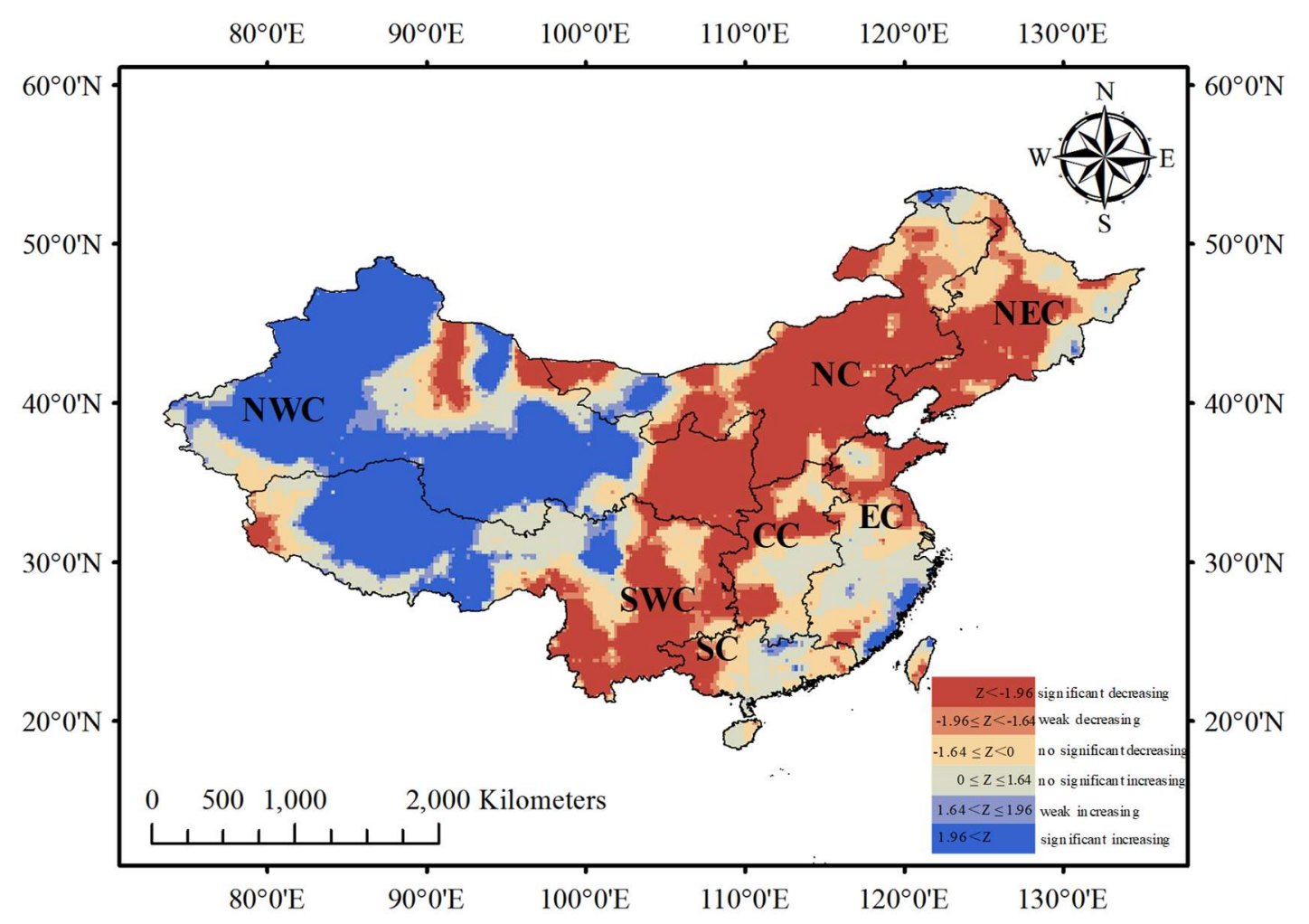

Figure 3. Spatial structure of sc_PDSI trends during 1960s-2010s.

\subsection{Heat Waves}

Figure 4 and Table 2 display the annual average number of heat wave occurrences at the decadal level over China. It can be seen that heat waves were more frequently occurred than droughts in China. There were two major areas in China that experienced high frequency heat waves in the 1960s, the first was CC and its surrounding areas in the adjacent NC, NWC, SWC, SC, and EC regions, and the second was the north and west parts of Xinjiang province. In the 1970s, the overall heat waves alleviated a little bit, as the area and degree of high frequent heat waves decreased in CC, and the rest high frequent heat waves were merely observed in the western Xinjiang province. CC continued to have a reduced heat wave situation in the 1980s because the high frequent heat wave center moved southward. Heat waves aggravated in the rest five regions of China, especially in NEC, SC, and SWC. The heat waves increased in the 1990s as entire China experienced much more frequent heat waves. One of the obvious changes was that the heat waves in the western Tibet became the severest with the annual average number of heat wave occurrences over 2.5 in this area. In the 2000s and 2010s, the heat wave exacerbated unprecedentedly, especially in the 2010s, all the regions had annual average number of heat wave occurrences over 3.2, and more than half China experienced more than 4 heat waves per year on average. Although the heat waves of different regions varied a lot in different decades, 
the overall heat waves for all the regions during the entire study period were quite similar, where the fluctuation of annual average number of heat wave occurrences was small.
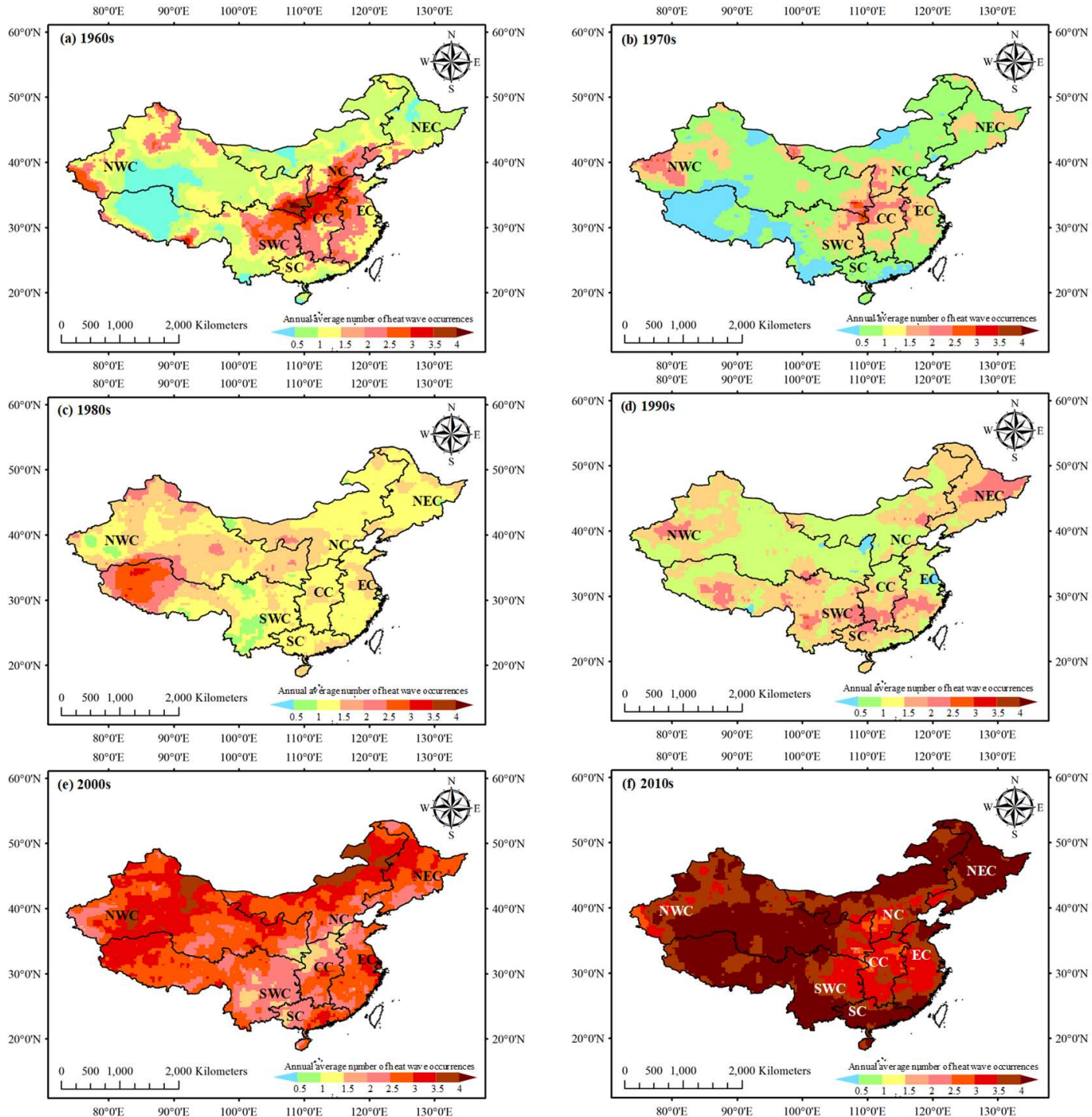

Figure 4. Spatial distribution of annual average number of heat wave occurrences at decadal level: (a) 1960s, (b) 1970s, (c) 1980s, (d) 1990s, (e) 2000s, and (f) 2010s.

Table 2. Annual average number of heat wave occurrences for the seven regions at the decadal level.

\begin{tabular}{cccccccc}
\hline Region & 1960s & 1970s & 1980s & 1990s & 2000s & 2010s & 1960s-2010s \\
\hline NEC & 0.92 & 0.91 & 1.37 & 1.40 & 2.29 & 4.19 & 1.85 \\
NC & 1.04 & 0.86 & 0.97 & 1.44 & 2.50 & 3.95 & 1.79 \\
NWC & 1.12 & 0.94 & 0.96 & 1.64 & 2.38 & 3.97 & 1.84 \\
SWC & 1.03 & 0.62 & 1.17 & 1.69 & 2.14 & 4.07 & 1.79 \\
CC & 2.07 & 1.28 & 1.15 & 1.35 & 1.79 & 3.26 & 1.82 \\
SC & 1.15 & 0.62 & 1.26 & 1.42 & 1.95 & 4.18 & 1.76 \\
EC & 1.61 & 1.01 & 1.08 & 1.40 & 2.14 & 3.60 & 1.81 \\
\hline
\end{tabular}

The spatial structure of daily maximum temperature trends analyzed by TFPW-MK method from the 1960s to 2010s are presented in Figure 5. The increasing trends of daily maximum temperature were dominant in China, consistent with decadal heat wave variations. TFPW-MK trend test was 
applied to the daily maximum temperature series at each grid over entire China, and then, the color of each grid was assigned according to the category of $Z$ value. Almost the entirety of China has experienced increased trends. With half of China experiencing weak increasing trends and the other half experiencing significant trends, significant increases occurred in NEC; northern NC; NWC, except Shanxi province and north and west of Xinjiang province; SWC except Guizhou, Chongqing, and Sichuan provinces; and the south of SC. The only region which presented decreasing trends was the border region between NWC and CC, where frequent heat waves were observed in the 1960s.

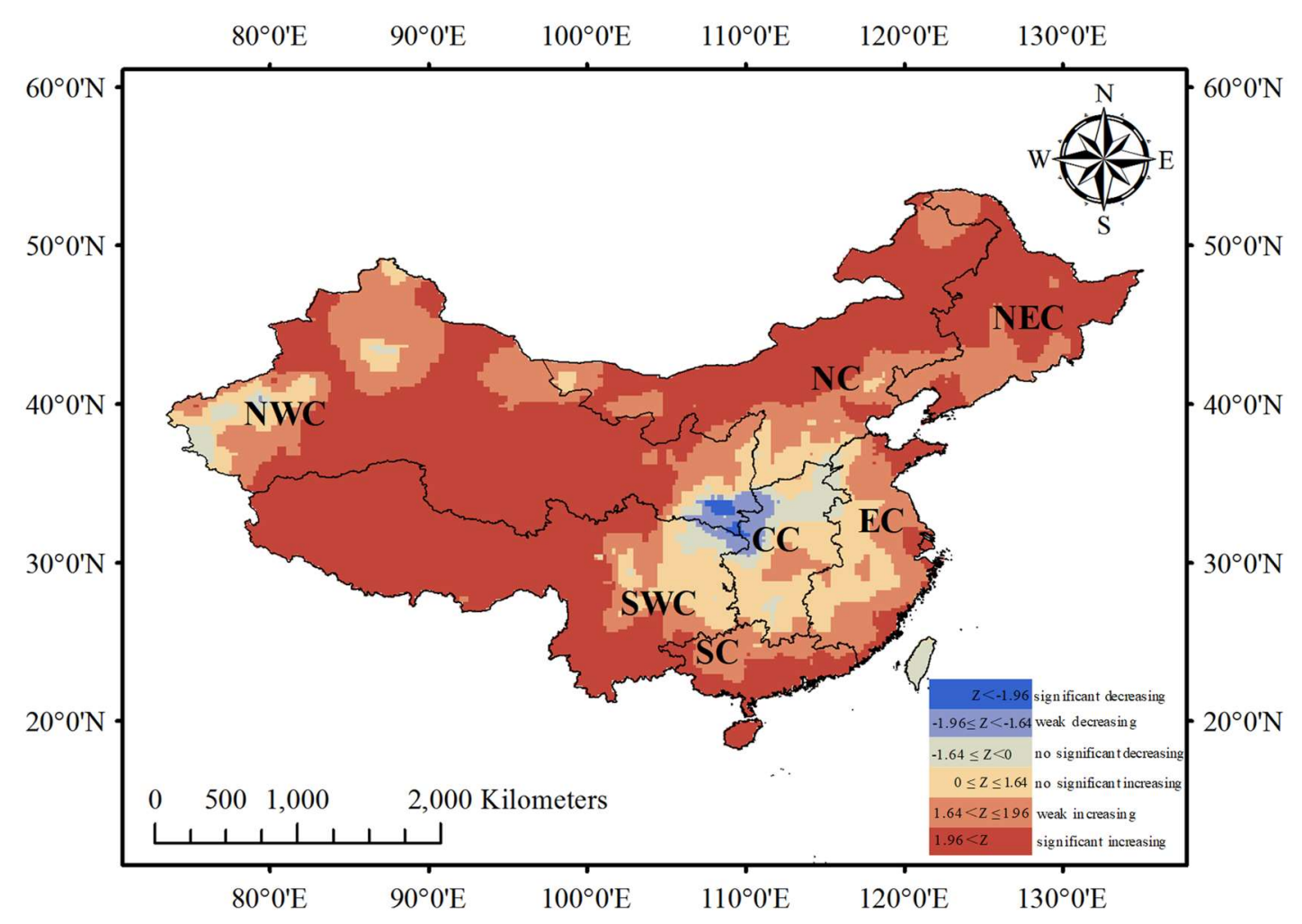

Figure 5. Spatial structure of daily maximum temperature trends from the 1960s to 2010s.

\subsection{Compound Drought and Heat Wave Events}

The compound drought and heat wave events over China were calculated based on the gridded sc_PDSI and daily maximum temperature series. Figure 6 and Table 3 display the annual average number of compound drought and heat wave occurrences at the decadal level over China. In the 1960s, only the north and west parts of Xinjiang province and the south half of SC presented frequent compound droughts and heat waves. This is due to the fact that these two areas were the only regions that both droughts and heat waves occurred frequently. For instance, the $\mathrm{CC}$ had the highest frequency of heat waves; however, the drought in CC was very mild in the 1960s. Owing to the heat wave reduction in SC and north part of Xinjiang province in the 1970s, the west of Xinjiang province was the only area that still had frequent compound droughts and heat waves. Because the high frequent drought affected area and high frequent heat wave affected area did not overlap in the 1980s, the compound droughts and heat waves were less frequent over entire China, as the annual average number of compound drought and heat wave occurrences for all the seven regions was below 0.2. The heat waves worsened over almost all of China after the 1990s, so the high frequency compound drought and heat wave area was mostly determined by droughts, and therefore the distribution of compound droughts and heat waves was very similar to the distribution of drought in 1990s, 2000s, and 2010s. 

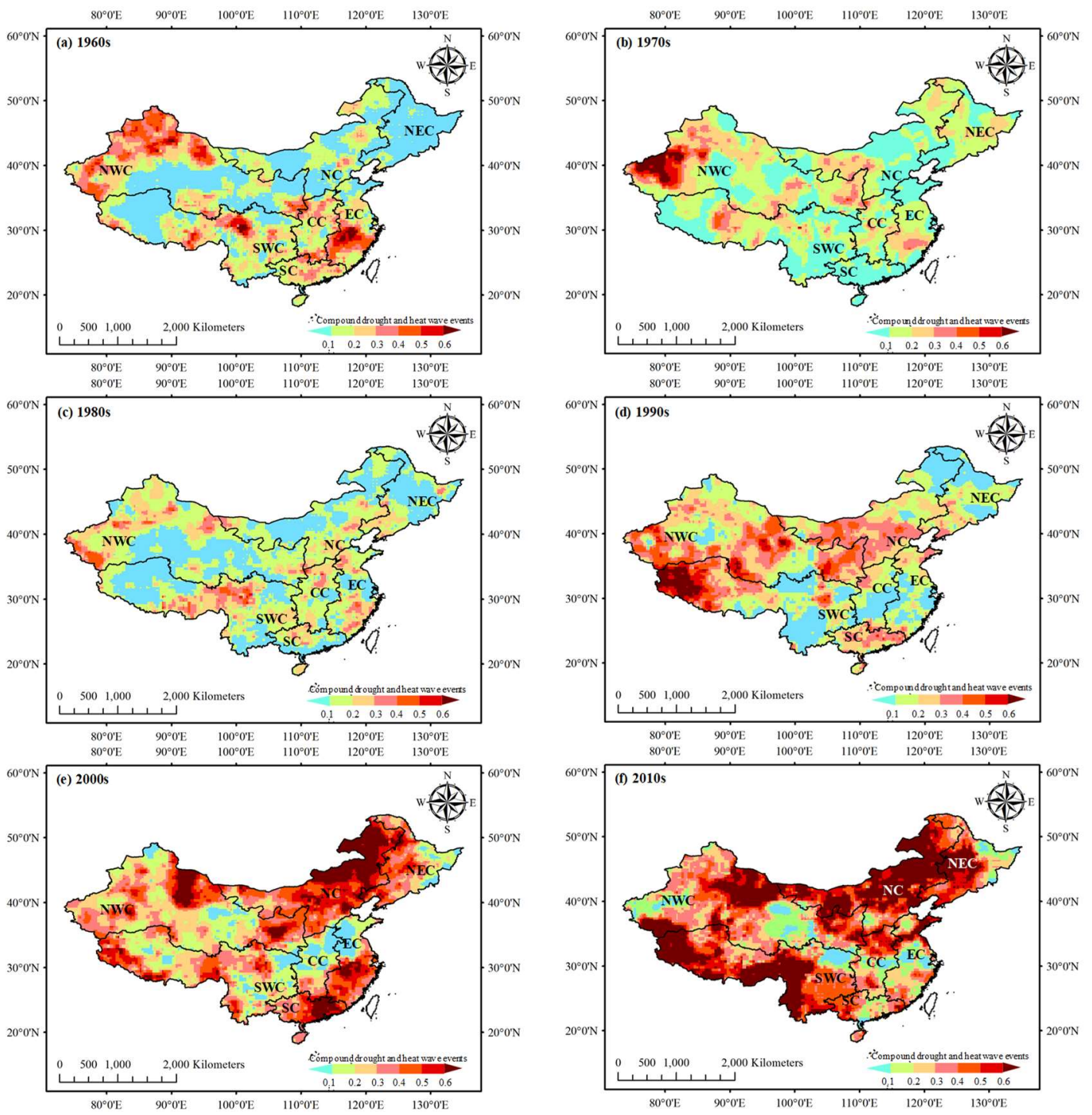

Figure 6. Spatial distribution of annual average number of compound drought and heat wave occurrences at decadal level: (a) 1960s, (b) 1970s, (c) 1980s, (d) 1990s, (e) 2000s, and (f) 2010s.

Table 3. Annual average number of compound drought and heat wave occurrences for the seven regions at the decadal level.

\begin{tabular}{cccccccc}
\hline Region & 1960s & 1970s & 1980s & 1990s & 2000s & 2010s & 1960s-2010s \\
\hline NEC & 0.03 & 0.14 & 0.10 & 0.13 & 0.34 & 0.45 & 0.20 \\
NC & 0.09 & 0.12 & 0.11 & 0.23 & 0.52 & 0.61 & 0.28 \\
NWC & 0.21 & 0.23 & 0.15 & 0.28 & 0.30 & 0.38 & 0.26 \\
SWC & 0.16 & 0.13 & 0.14 & 0.25 & 0.29 & 0.53 & 0.25 \\
CC & 0.22 & 0.15 & 0.17 & 0.14 & 0.19 & 0.34 & 0.20 \\
SC & 0.27 & 0.14 & 0.17 & 0.15 & 0.34 & 0.31 & 0.23 \\
EC & 0.22 & 0.06 & 0.13 & 0.27 & 0.48 & 0.35 & 0.25 \\
\hline
\end{tabular}

By definition, the number of compound drought and heat wave events is always no higher than the numbers of droughts and heat waves. Since the frequency of the drought occurrence did not increase significantly in China, so we illustrate the increase of compound droughts and heat waves by showing the variations of the percentage of compound droughts and heat waves to droughts from 1961-2017, shown in Figure 7. It is very apparent that all seven regions presented significant increasing 
trends. In the 1960s, the average percentages for most regions were less than 30\%, while in the 2010s, the percentages were usually higher than $90 \%$. The results indicated that almost every drought that occurred in the 2010s was accompanied by one or more heat waves, while $70 \%$ droughts occurred in 1960s without a heat wave. The weakest increasing trend was noticed in CC, this is due to high frequency of heat waves in the 1960s in this area, so the percentage during that period was high.
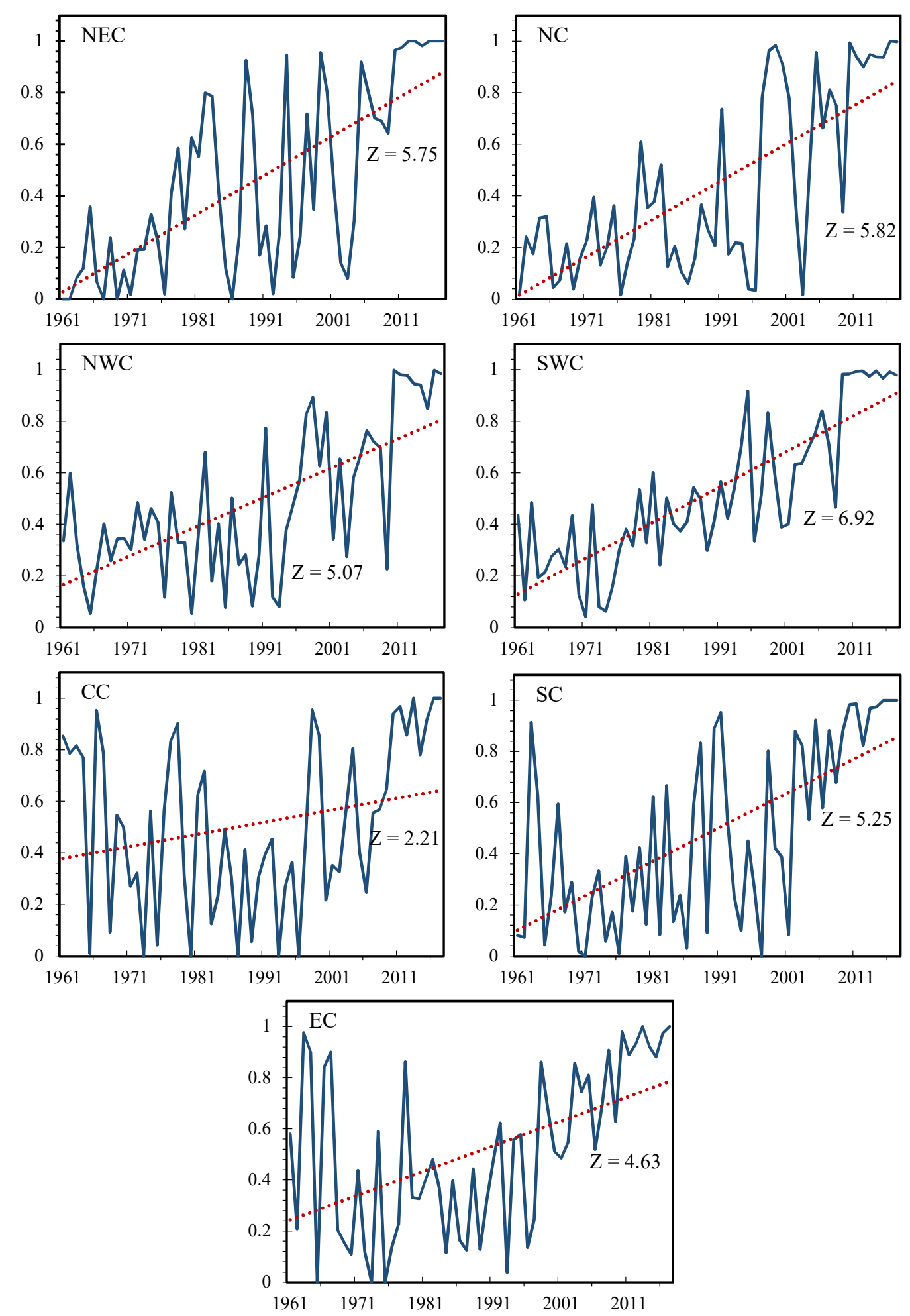

Figure 7. Percentage of compound droughts and heat waves to droughts for the seven regions from 1961-2017. 


\section{Discussion}

This paper mainly focuses on the occurrence of droughts, heat waves, and compound of both, rather than the index values that most scholars have paid attention to in the past. As for drought, regionality is quite evident. Chen et al. [48] pointed out that drought indicated by SPEI and SPI is observed to have increased evidently across almost entire China. This increase is much stronger in the north compared to the south, especially in NWC and NC. Part of the result is consistent with our trend analysis of sc_PDSI values that the droughts show a significant increasing trend in NC. While except the Shaanxi province and the northwest of Xinjiang province, the rest areas in NWC present significant decreasing trend. The variations of drought occurrence confirm again that most areas in NWC present a decreasing drought trend as the annual average number of drought occurrences decreases from the 1960s to 2010s. He et al. [49] identified five meteorological drought-prone regions, i.e., the Huang-Huai-Hai Plain, Northeast China, Southwest China, coastal Southern China, and Northwest China. Our results show that droughts occur frequently in NWC in the 1960s, and over time, the frequent drought-affected areas gradually shift to NEC and NC. It is difficult to compare different results of drought, because the differences in the period of analysis, data sources, the number of stations (or gridded data), and drought indices collectively contributed to inconsistencies in the results [50]. For heat waves, accelerated worsening of heat wave in China has been observed and acknowledged by many researchers [51-53]. Our results demonstrate again that the warming trend is unprecedented. Although the frequency of heat waves in China has increased, there are still obvious regional distinctions that the areas showing significant increase are NEC, northern NC, part of NWC, and part of SWC. The rising trend of heat wave frequency is more significant than that of droughts. Wu et al. [35] investigated changes in the frequency of compound droughts and heat waves in China and concluded that an increase in the frequency and spatial extent was mainly shown in NC, SC, and SWC, while our results show that the most significant increase is NEC, NC, and SWC.

Anomalies in large-scale circulation are vital for trends of both droughts and heat waves. Historically, drought analysis has focused on the impacts of how precipitation deficits pose on droughts. However, high evaporative demand due to heat waves can also dry soils and increase drought severity. The results of this study highlight the increasing possibility of drought occurrences companioned by heat waves. Therefore, comprehensively account for the relative effects of precipitation deficits, heat waves, and other variables in producing droughts will be key for improved understanding of droughts. Land surface modeling will be an important diagnostic tool in such efforts, though more complete representation of land-atmosphere coupling in models definitely have high standards for observations [54].

\section{Summary and Conclusions}

This paper provides a comprehensive analysis of spatio-temporal patterns of droughts, heat waves, and the compound of both over China from 1961 to 2017. The high spatial resolution gridded sc_PDSI and daily maximum temperature datasets are used to quantify the characteristics of droughts and heat waves, respectively. Therefore, the results are credible and can be used to assist with drought and heat wave mitigation.

Our results indicate that NC and NWC are the two regions that experienced the most frequent droughts, while the CC is the least drought-affected region. The increase in the occurrence of heat wave is very significant over the entire China, the occurrence of heat waves began to increase in the 1990s and has reached an unprecedented severity since 2000. Furthermore, the variations of the percentage of compound drought and heat wave to drought were analyzed. All the seven regions presented significant increasing trends, more than $90 \%$ drought events occurred in the 2010 s were accompanied by one or more heat waves. The significant increasing trends of compound droughts and heat waves detected in this paper clearly show that considering the compound disasters and their impacts on socio-environmental system are basic preconditions for drought and heat wave management. In addition, the comprehensive analysis of compound droughts and heat waves can 
help to establish resilience and adaptive policies for droughts and heat waves, which could definitely contribute to the Agenda 2030 [55], especially for Goal 13: take urgent action to combat climate change and its impacts.

However, beyond Figures 3 and 5 presenting the spatial distribution of sc_PDSI and daily maximum temperature trends that effectively considered frequency, severity, and duration of drought and heat wave, the rest of the analyses in this paper are all about the occurrence of droughts, heat waves, and the compound of both. In the future, it is necessary to conduct comprehensive studies of frequency, intensity, and duration of compound droughts and heat waves which would provide a more useful reference for these meteorological disasters risk management.

Author Contributions: L.Y. designed the study and wrote the manuscript; K.S. performed the experiments and analyzed the data; Z.X. assisted with the results and discussion sections; C.W. and C.Z. provided feedback on the structure of the manuscript and reviewed the manuscript.

Funding: This research was jointly supported by the National Natural Science Foundation of China (nos. 91647201, 51709033) and the National Key Research and Development Program of China (no. 2017YFC0406001).

Acknowledgments: Special thanks are given to the two anonymous reviewers and academic editor for their constructive remarks.

Conflicts of Interest: The authors declare no conflict of interest.

\section{References}

1. Seneviratne, S.I.; Nicholls, N.; Easterling, D.; Goodess, C.M.; Kanae, S.; Kossin, J.; Luo, Y.; Marengo, J.; McInnes, K.; Rahimi, M. Managing the Risks of Extreme Events and Disasters to Advance Climate Change Adaptation: Special Report of the Intergovernmental Panel on Climate Change; Cambridge University Press: Cambridge, NY, USA, 2012.

2. Mishra, A.K.; Singh, V.P. Changes in extreme precipitation in Texas. J. Geophys. Res. Atmos. $2010,115$. [CrossRef]

3. Horton, R.M.; Mankin, J.S.; Lesk, C.; Coffel, E.; Raymond, C. A review of recent advances in research on extreme heat events. Curr. Clim. Chang. Rep. 2016, 2, 242-259. [CrossRef]

4. Alfieri, L.; Bisselink, B.; Dottori, F.; Naumann, G.; de Roo, A.; Salamon, P.; Wyser, K.; Feyen, L. Global projections of river flood risk in a warmer world. Earths Future 2017, 5, 171-182. [CrossRef]

5. Dosio, A.; Mentaschi, L.; Fischer, E.M.; Wyser, K. Extreme heat waves under $1.5^{\circ} \mathrm{C}$ and $2{ }^{\circ} \mathrm{C}$ global warming. Environ. Res. Lett. 2018, 13, 054006. [CrossRef]

6. Slootweg, R.; Jones, M. Resilience thinking improves SEA: A discussion paper. Impact Assess. Proj. Apprais. 2011, 29, 263-276.

7. Szewrański, S.; Świąder, M.; Kazak, J.K.; Tokarczyk-Dorociak, K.; van Hoof, J. Socio-Environmental Vulnerability Mapping for Environmental and Flood Resilience Assessment: The Case of Ageing and Poverty in the City of Wrocław, Poland. Integr. Environ. Assess. Manag. 2018, 14, 592-597. [CrossRef] [PubMed]

8. Mazdiyasni, O.; AghaKouchak, A. Substantial increase in concurrent droughts and heatwaves in the United States. Proc. Natl. Acad. Sci. USA 2015, 112, 11484-11489. [CrossRef]

9. Hao, Z.; AghaKouchak, A.; Phillips, T.J. Changes in concurrent monthly precipitation and temperature extremes. Environ. Res. Lett. 2013, 8, 034014. [CrossRef]

10. Sharma, S.; Mujumdar, P. Increasing frequency and spatial extent of concurrent meteorological droughts and heatwaves in India. Sci. Rep. 2017, 7, 15582. [CrossRef]

11. Hao, Z.; Hao, F.; Singh, V.P.; Xia, Y.; Shi, C.; Zhang, X. A multivariate approach for statistical assessments of compound extremes. J. Hydrol. 2018, 565, 87-94. [CrossRef]

12. Seneviratne, S.I.; Nicholls, N.; Easterling, D.; Goodess, C.M.; Kanae, S.; Kossin, J.; Luo, Y.; Marengo, J.; McInnes, K.; Rahimi, M. Changes in climate extremes and their impacts on the natural physical environment: An overview of the IPCC SREX report. In Proceedings of the EGU General Assembly Conference Abstracts, Vienna, Austria, 22-27 April 2012; Volume 14, p. 12566.

13. Leonard, M.; Westra, S.; Phatak, A.; Lambert, M.; van den Hurk, B.; McInnes, K.; Risbey, J.; Schuster, S.; Jakob, D.; Stafford-Smith, M. A compound event framework for understanding extreme impacts. Wiley Interdiscip. Rev. Clim. Chang. 2014, 5, 113-128. [CrossRef] 
14. Zscheischler, J.; Westra, S.; Hurk, B.J.; Seneviratne, S.I.; Ward, P.J.; Pitman, A.; AghaKouchak, A.; Bresch, D.N.; Leonard, M.; Wahl, T. Future climate risk from compound events. Nat. Clim. Chang. 2018, 1, 469-477. [CrossRef]

15. Dai, A. Drought under global warming: A review. Wiley Interdiscip. Rev. Clim. Chang. 2011, 2, 45-65. [CrossRef]

16. Stocker, T.; Qin, D.; Plattner, G.; Tignor, M.; Allen, S.; Boschung, J.; Nauels, A.; Xia, Y.; Bex, V.; Midgley, P. IPCC, 2013: Climate Change 2013: The Physical Science Basis. In Contribution of Working Group I to the Fifth Assessment Report of the Intergovernmental Panel on Climate Change; Cambridge University Press: Cambridge, UK; New York, NY, USA, 2013; 1535p.

17. Sternberg, T. Regional drought has a global impact. Nature 2011, 472, 169. [CrossRef]

18. Kenney, W.L.; Craighead, D.H.; Alexander, L.M. Heat waves, aging, and human cardiovascular health. Med. Sci. Sports Exerc. 2014, 46, 1891. [CrossRef] [PubMed]

19. Ciais, P.; Reichstein, M.; Viovy, N.; Granier, A.; Ogée, J.; Allard, V.; Aubinet, M.; Buchmann, N.; Bernhofer, C.; Carrara, A. Europe-wide reduction in primary productivity caused by the heat and drought in 2003. Nature 2005, 437, 529. [CrossRef] [PubMed]

20. Vautard, R.; Honore, C.; Beekmann, M.; Rouil, L. Simulation of ozone during the August 2003 heat wave and emission control scenarios. Atmos. Environ. 2005, 39, 2957-2967. [CrossRef]

21. Mueller, B.; Seneviratne, S.I. Hot days induced by precipitation deficits at the global scale. Proc. Natl. Acad. Sci. USA 2012, 109, 12398-12403. [CrossRef]

22. Stéfanon, M.; Drobinski, P.; D'Andrea, F.; Lebeaupin-Brossier, C.; Bastin, S. Soil moisture-temperature feedbacks at meso-scale during summer heat waves over Western Europe. Clim. Dyn. 2014, 42, 1309-1324. [CrossRef]

23. Teskey, R.; Wertin, T.; Bauweraerts, I.; Ameye, M.; McGuire, M.A.; Steppe, K. Responses of tree species to heat waves and extreme heat events. Plant Cell Environ. 2015, 38, 1699-1712. [CrossRef]

24. Seneviratne, S.I.; Corti, T.; Davin, E.L.; Hirschi, M.; Jaeger, E.B.; Lehner, I.; Orlowsky, B.; Teuling, A.J. Investigating soil moisture-climate interactions in a changing climate: A review. Earth Sci. Rev. 2010, 99, 125-161. [CrossRef]

25. Miralles, D.G.; Gentine, P.; Seneviratne, S.I.; Teuling, A.J. Land-atmospheric feedbacks during droughts and heatwaves: State of the science and current challenges. Ann. N. Y. Acad. Sci. 2018, 1436, 19-35. [CrossRef] [PubMed]

26. Cong, Z.; Yang, D.; Gao, B.; Yang, H.; Hu, H. Hydrological trend analysis in the Yellow River basin using a distributed hydrological model. Water Resour. Res. 2009, 45. [CrossRef]

27. Lin, W.; Wen, C.; Wen, Z.; Gang, H. Drought in Southwest China: A review. Atmos. Ocean. Sci. Lett. 2015, $8,339-344$.

28. Sun, Y.; Zhang, X.; Zwiers, F.W.; Song, L.; Wan, H.; Hu, T.; Yin, H.; Ren, G. Rapid increase in the risk of extreme summer heat in Eastern China. Nat. Clim. Chang. 2014, 4, 1082. [CrossRef]

29. Bai, L.; Ding, G.; Gu, S.; Bi, P.; Su, B.; Qin, D.; Xu, G.; Liu, Q. The effects of summer temperature and heat waves on heat-related illness in a coastal city of China, 2011-2013. Environ. Res. 2014, 132, 212-219. [CrossRef] [PubMed]

30. Gu, S.; Huang, C.; Bai, L.; Chu, C.; Liu, Q. Heat-related illness in China, summer of 2013. Int. J. Biometeorol. 2016, 60, 131-137. [CrossRef] [PubMed]

31. Lipiec, J.; Doussan, C.; Nosalewicz, A.; Kondracka, K. Effect of drought and heat stresses on plant growth and yield: A review. Int. Agrophys. 2013, 27, 463-477. [CrossRef]

32. Zhang, Y.; Li, G.; Ge, J.; Li, Y.; Yu, Z.; Niu, H. sc_PDSI is more sensitive to precipitation than to reference evapotranspiration in China during the time period 1951-2015. Ecol. Indic. 2019, 96, 448-457. [CrossRef]

33. Lu, H.; Mo, X.; Liu, S. Intercomparison of three indices for addressing drought variability in North China Plain during 1962-2012. Proc. Int. Assoc. Hydrol. Sci. 2015, 366, 141-142. [CrossRef]

34. Wei, J.; Ma, Z. Comparison of Palmer drought severity index, percentage of precipitation anomaly and surface humid index. Acta Geogr. Sin. 2003, 58, 117-124.

35. Wu, X.; Hao, Z.; Hao, F.; Li, C.; Zhang, X. Spatial and Temporal Variations of Compound Droughts and Hot Extremes in China. Atmosphere 2019, 10, 95. [CrossRef]

36. Easterling, D.R.; Evans, J.; Groisman, P.Y.; Karl, T.R.; Kunkel, K.E.; Ambenje, P. Observed variability and trends in extreme climate events: A brief review. Bull. Am. Meteorol. Soc. 2000,81,417-426. [CrossRef]

37. Li, X.; You, Q.; Ren, G.; Wang, S.; Zhang, Y.; Yang, J.; Zheng, G. Concurrent droughts and hot extremes in Northwest China from 1961 to 2017. Int. J. Climatol. 2018. [CrossRef] 
38. Perkins, S.E.; Alexander, L.V. On the measurement of heat waves. J. Clim. 2013, 26, 4500-4517. [CrossRef]

39. Data, C. Guidelines on Analysis of Extremes in A Changing Climate in Support of Informed Decisions for Adaptation; World Meteorological Organization: Geneve, Switzerland, 2009.

40. Mann, H.B. Nonparametric tests against trend. Econom. J. Econom. Soc. 1945, 13, 245-259. [CrossRef]

41. Kendall, M.G. Rank Correlation Methods; Springer: Berlin/Heidelberg, Germany, 1955.

42. Serrano, A.; Mateos, V.; Garcia, J. Trend analysis of monthly precipitation over the Iberian Peninsula for the period 1921-1995. Phys. Chem. Earth Part B Hydrol. Ocean. Atmos. 1999, 24, 85-90. [CrossRef]

43. Yue, S.; Pilon, P.; Phinney, B.; Cavadias, G. The influence of autocorrelation on the ability to detect trend in hydrological series. Hydrol. Process. 2002, 16, 1807-1829. [CrossRef]

44. Serinaldi, F.; Kilsby, C.G.; Lombardo, F. Untenable nonstationarity: An assessment of the fitness for purpose of trend tests in hydrology. Adv. Water Resour. 2018, 111, 132-155. [CrossRef]

45. Clarke, R.T. On the (mis)use of statistical methods in hydro-climatological research. Hydrol. Sci. J. 2010, 55, 139-144. [CrossRef]

46. Poppick, A.; Moyer, E.J.; Stein, M.L. Estimating trends in the global mean temperature record. Adv. Stat. Climatol. Meteorol. Oceanogr. 2017, 3, 33-53. [CrossRef]

47. Wang, W.; Zhu, Y.; Xu, R.; Liu, J. Drought severity change in China during 1961-2012 indicated by SPI and SPEI. Nat. Hazards 2014, 75, 2437-2451. [CrossRef]

48. Chen, H.-P.; Sun, J.-Q. Drought response to air temperature change over China on the centennial scale. Atmos. Ocean. Sci. Lett. 2015, 8, 113-119.

49. He, J.; Yang, X.; Li, Z.; Zhang, X.; Tang, Q. Spatiotemporal Variations of Meteorological Droughts in China During 1961-2014: An Investigation Based on Multi-Threshold Identification. Int. J. Disaster Risk Sci. 2016, 7, 63-76. [CrossRef]

50. Smith, T.T.; Zaitchik, B.F.; Gohlke, J.M. Heat waves in the United States: Definitions, patterns and trends. Clim. Chang. 2013, 118, 811-825. [CrossRef] [PubMed]

51. Sun, Y.; Hu, T.; Zhang, X. Substantial Increase in Heat Wave Risks in China in a Future Warmer World. Earths Future 2018, 6, 1528-1538. [CrossRef]

52. Sun, Z.; Ouyang, Z.; Zhao, J.; Li, S.; Zhang, X.; Ren, W. Recent rebound in observational large-pan evaporation driven by heat wave and droughts by the Lower Yellow River. J. Hydrol. 2018, 565, 237-247. [CrossRef]

53. Wang, P.; Tang, J.; Sun, X.; Wang, S.; Wu, J.; Dong, X.; Fang, J. Heat Waves in China: Definitions, Leading Patterns, and Connections to Large-Scale Atmospheric Circulation and SSTs. J. Geophys. Res. Atmos. 2017, 122, 10679-10699. [CrossRef]

54. Kelly, M.G. Temperature and Drought, A Science Assessment By A Subgroup Of The Drought Task Force; California Department of Water Resources: Sacramento, CA, USA, 2015.

55. Colglazier, W. Sustainable development agenda: 2030. Science 2015, 349, 1048-1050. [CrossRef] 